\title{
Constant Data Value
}

National Cancer Institute

\section{Source}

National Cancer Institute. Constant Data Value. NCI Thesaurus. Code C64359.

Predefined values for some elements (fields) on a data entry workform. 